\title{
Patent-drug price board to review guidelines
}

The tribunal in charge of regulating drug prices is reviewing its guidelines in light of an increase in the price of $35 \%$ of all patented drugs last year.

In a Mar. 9 discussion paper, the Patented Medicine Prices Review Board (PMPRB) outlined concerns that price stability could be under some "strain" and asked for comments by May 9.

"The proportion of drug [price] increases is somewhat out of the norm," says Barbara Ouellet, PMPRB's new executive director. "It created questions in our minds over whether this is unique."

The board will not know un$\vec{\delta}$ til later this spring what the price increases translate into in dollar figures.

Operating at arm's length from government, the PMPRB is a quasi-judicial tribunal created $\AA$ in 1987 to regulate the price of patented drugs sold in Canada. Under current guidelines, manufacturers cannot increase prices above the consumer price index.

Rx\&D, Canada's Researchbased Pharmaceutical Companies, refused to comment on the discussion paper until it sends its comments to the board.

The paper presents 3 possible frameworks, the first being to maintain the status quo.

The second calls for changes to the Patented Medicine Regulations (1994) requiring manufacturers to notify the board in advance of any price change so it can calculate whether they fall within the guidelines. Currently, manufacturers are obliged to inform the board within 6 months of a price change.

Although this is presented as a proposal, the PMPRB has already applied for this amendment to the Patented Medicine Regulations, with comments due Apr. 15.

The third framework requires patentees to apply in advance of a price change, like the second framework, and to also justify the increase. "The PMPRB would then make a determination on both the appropriateness of the increase and then on the extent of the increase allowed up to a non-excessive maximum," the paper states.

Ouellet says she expects numerous submissions. The board will recommend action to the government.

Canadian drug prices have been stable since 1998 and are now comparable with 6 European countries. In 1987, Canadian prices were $23 \%$ higher than the median international prices. However, retail spending on drugs increased $10.5 \%$ in 2002 (to $\$ 18.4$ billion). - Barbara Sibbald, CMAJ 